\title{
Graphene Functionalized by Doping and Defects for Gas Sensor Application
}

\author{
Qingwei Zhang, Yanjie Xu, Jun'an Zhang, 'Yunhua Lu, and Jiangling Tian \\ School of Artificial Intelligence, Chongqing University of Technology, Chongqing, Yubei District 400000, China
}

(Received January 15, 2021; accepted March 16, 2021)

Keywords: graphene, adsorption, sensor application, dopant, defect, functionalization

Graphene, as a two-dimensional (2D) carbon material, has been a research focus in the field of sensors since its discovery owing to its physical and chemical properties. However, the zeroband-gap characteristic of graphene places many restrictions on its application in sensors. To expand the application potential of graphene materials in the field of detection, various surface functionalization methods have been developed. The most common and useful methods of functionalization are doping and the introduction of defects. This paper mainly reviews the state-of-the-art work on gas sensing applying defective and doped graphene. The effects of defect and heteroatom codoping on the gas-sensing properties of graphene are also discussed, and the key research directions of functionalized graphene chemical sensors in the future are proposed.

\section{Introduction}

Gas sensors, with their ability to detect combustible, explosive, and toxic gases, have been widely used in safety monitoring and process control in residences, industry, and mining. However, sensitivity and selectivity remain bottlenecks for current solid gas-sensing devices. As one of the first discovered members of the two-dimensional (2D) material family, graphene has been widely used in photocatalysts, lithium electronic batteries, supercapacitors, gas sensors, and field-effect transistors since its discovery in 2004. ${ }^{(1)}$ Its high carrier mobility and density and low intrinsic noise are promising for detection with a high signal-to-noise ratio. ${ }^{(2)}$ Every atom of a graphene film is exposed to the environment, making the conductance of graphene highly sensitive to local electrical and chemical perturbations. ${ }^{(3)}$ These exceptional properties are particularly useful for the development of gas sensors.

The gas detection properties of graphene were initially investigated by Novoselov et al. ${ }^{(1)}$ However, almost three years later, the gas-sensitive properties of graphene have been systematically reported, in which it was demonstrated that graphene can detect gas molecules at the single-molecule level owing to its low electronic noise. ${ }^{(4)}$ Unfortunately, the superior characteristics of graphene are difficult to achieve under actual sensing conditions, ${ }^{(5-7)}$ and the

*Corresponding author: e-mail: zja2017@cqut.edu.cn https://doi.org/10.18494/SAM.2021.3296 
low sensitivity and long recovery time of graphene-based sensors have limited their further development.

Although the unique characteristics of graphene make it suitable as a sensor material, sensors made of pristine graphene still suffer from some disadvantages, the most prominent of which is the small number of dangling bonds on the surface, which is the main factor limiting the chemisorption of target molecules on the graphene surface. ${ }^{(8)}$ It has been reported that introducing appropriate doping elements and defects can improve the sensitivity and response of graphene materials to gas molecules. ${ }^{(9)}$

To further improve the sensor response to target molecules, various approaches to the surface functionalization of graphene have been intensively studied. Zhou et al. explored the adsorption of NO gas on defective graphene, and by analyzing the electrical conductivity and structural properties, they found that defects can enhance the adsorption capacity of graphene for NO. ${ }^{(10)}$ Arunragsa et al. fabricated a novel room-temperature gas sensor by drop-casting hydroxylfunctionalized graphene quantum dots (OH-GQDs) onto an interdigitated nickel electrode. ${ }^{(11)}$ Salih and Ayesh investigated the effects of passivation and doping of an armchair graphene nanoribbon (AGNR) on the sensing performance for the detection of $\mathrm{CO}$ and $\mathrm{CO}_{2}$ gases, and demonstrated that doping a H-AGNR or N-AGNR (an AGNR passivated with hydrogen or nitrogen, respectively) with $\mathrm{Pt}$ is a promising technique for enhancing the sensing properties of AGNRs. ${ }^{(12)}$ Note that the codoping of graphene and traditional gas-sensitive materials (such as noble metals, transition metals, and alkali metals) results in materials that exhibit not only the individual properties of the traditional gas-sensing materials and graphene but also additional novel features due to the synergistic effect between them. ${ }^{(13-18)}$

The operational principle of graphene sensors is based on the change in electrical conductivity when the gas molecules and the device interact; the gas molecules adsorbed on graphene induce a change in its electronic structure, ${ }^{(19-21)}$ and the electrical conductivity of graphene as an electron donor or acceptor increases or decreases rapidly. Researchers previously sought to improve the detection performance of gas sensors by investigating the characteristics of graphene. ${ }^{(22-25)}$ Graphene can be made magnetic by introducing defects, such as lattice vacancies (which directly remove carbon atoms), ${ }^{(26-28)}$ chemisorption atoms, ${ }^{(29-33)}$ and point defects such as heteroatoms to replace carbon atoms. Point defects destroy the $\mathrm{sp}^{2}$ lattice structure and induce electron magnetization. In addition, the surface of graphene can be modified by metal nanoparticles (NPs) and organic polymers and shaped into a nanostructure mesh. ${ }^{(34)}$ Furthermore, graphene has been treated with ultraviolet (UV)/ozone to introduce oxygen defects. ${ }^{(35)}$

As observed in published research, functionalization can impart selectivity to graphenebased gas sensors, as well as improve their sensitivity. Liang et al. found that doping graphene with $\mathrm{Ca}$ atoms significantly enhanced its adsorption capacity of $\mathrm{H}_{2} \mathrm{O}, \mathrm{NH}_{3}, \mathrm{CO}, \mathrm{NO}$, and $\mathrm{NO}_{2}$, with the strongest affinity shown to $\mathrm{NO}_{2}$ gas molecules. ${ }^{(36)} \mathrm{NP}$ decoration and other functionalizations of graphene surfaces have overcome the inherent non-selectivity of bare graphene in gas-sensing applications. ${ }^{(37,38)}$

However, most of the existing research on the adsorption of functionalized graphene to gases is focused on the modification of a single mode (structural defects or doping with heterogeneous atoms). There have been few studies on the adsorption of characteristic gases on dual-mode- 
modified graphene, i.e., graphene containing both structural defects and heterogeneous atoms. Graphene functionalized by a combination of defects and doping is currently attracting considerable attention. ${ }^{(39-43)}$ The goal of codoping is to create superior synergy through joint contributions to a particular property. In the past few years, theoretical and experimental advances have demonstrated that codoping is indeed a promising route to achieving highperformance sensors.

The molecules or metals used in surface functionalization change the chemical and/or physical states of the target molecules, and these changes are detected by graphene as a change in resistance. Although some reviews on graphene-based gas sensors have recently been published, ${ }^{(44-47)}$ little attention has been paid to functionalized graphene-based gas sensors. However, growing effort has been devoted to the development of these sensors. Consequently, it is appropriate and necessary to systematically evaluate the theoretical analysis and experimental investigation of graphene functionalization for gas detection. Here, we introduce functionalized graphene-based gas sensors by dividing them into three types according to their sensing principles, i.e., gas sensors employing graphene doped with atoms, graphene containing defects, and binary graphene-based hybrids.

\section{Gas Sensors Based on Doped Graphene Materials}

Intrinsic graphene (IG) has weak interaction with gas molecules owing to its relatively stable physical and chemical properties, which affects the sensitivity of graphene in gas molecular detection. On the basis of a series of theoretical and experimental studies, it has been found that doping impurities or introducing defects can significantly improve the adsorption capacity of gas molecules on graphene and enhance the adsorption sensitivity of graphene to gas molecules, and that doping with different impurities will imbue graphene with selectivity to different gases. ${ }^{(48,49)}$

\subsection{Electric field doping}

Dopants ranging from metal NPs to halogen atoms and molecules have been successfully used to improve figures of merit such as sensitivity, recovery time, and especially selectivity. Furthermore, it has been reported that the properties of low-dimensional materials can be modulated by a perpendicular electric field. ${ }^{(50,51)}$ For example, $\mathrm{Lv}$ et al. found that $\mathrm{N}_{2} \mathrm{O}$ molecules can be easily adsorbed on Al-doped graphene (AlG) under an electric field. ${ }^{(52)}$ RezaeiSameti and Rakhshi proposed that Mn and Tc doped with static electric fields might be a good strategy for enhancing the $\mathrm{CO}$ adsorption capability of the surface of graphene and improving its applicability to sensing. ${ }^{(53)}$

One way to improve the sensing performance of graphene is to regulate the bandgap width by applying an electric field in a vertical plane. Tanaka et al. studied the effect of the gate-induced electric field on the response of a surface-functionalized graphene sensor and found that the introduction of electric field regulation on the graphene surface can enhance the sensing ability of functionalized graphene. ${ }^{(54)}$ Figure 1 shows a schematic diagram of the cross-sectional device 


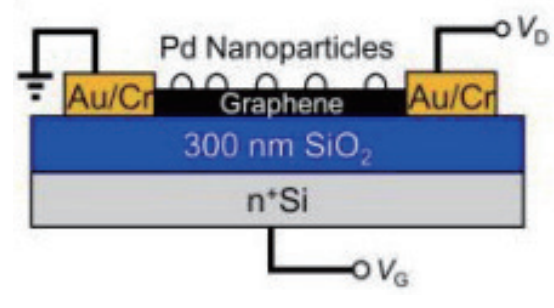

(a)

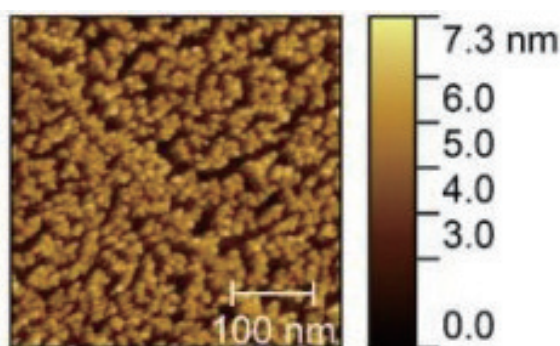

(b)

Fig. 1. (Color online) (a) Schematic diagram of cross section and bias condition of Pd-NP-decorated graphene sensor. (b) AFM image of Pd-NP-decorated graphene surface. The bright dots are Pd NPs. ${ }^{(54)}$

structure and an AFM image of the graphene surface decorated with Pd NPs. In their experiments, graphene modified with Pd NPs was used as a sensing material. The gate voltage was found to be dependent on the drain current and the modified graphene was significantly more responsive to hydrogen. Note that the enhancement of the reaction requires that the potential transfer due to surface functionalization must have the opposite sign to that due to the target molecule. The asymmetric transmission of carriers successfully explains the enhancement of the sensor response.

Omidi and Faizabadi demonstrated that the detection range of graphene sensors is affected by in-plane electric or magnetic fields. ${ }^{(55)}$ By tuning the perpendicular magnetic field or in-plane electric field, they discussed the density of states and current of an armchair hexagonal graphene ring as it adsorbs gas molecules $\left(\mathrm{CO}, \mathrm{NO}, \mathrm{CO}_{2}\right.$, and $\left.\mathrm{NH}_{3}\right)$. They found that the difference between the current values of different gas molecules increased owing to a change in the density of states, which provides suitable conditions for identifying more types of adsorbed gas molecules. At nonzero magnetic and electric fields, the symmetry of the density of states of the graphene ring is lost with the adsorption of gas molecules. The current voltage with respect to the polarization voltage shows that the current value depends on the amount of gas adsorption and the type of gas molecule.

\subsection{Chemical doping}

\subsubsection{Molecule doping}

Molecule doping provides a suitable way to modify the electronic structure of graphene by exploiting its sensitivity to the surrounding environment. ${ }^{(56)}$ In this method, molecules are adsorbed on graphene to realize surface transfer doping, thus forming ordered molecular arrays. $^{(57)}$

Mortazavi Zanjani et al. explored the effectiveness of $\mathrm{NO}_{2}$ molecule doping as a means of enhancing the sensing ability of graphene for $\mathrm{NH}_{3}$ gas molecules at room temperature. ${ }^{(35)}$ The experimental results showed that doping $\mathrm{NO}_{2}$ molecules increased the sensitivity of a graphene sensor to $\mathrm{NH}_{3}$ adsorption by one order of magnitude. After doping, the detection limit of the 
$\mathrm{NO}_{2}$-doped graphene sensor for $\mathrm{NH}_{3}$ molecules was $200 \mathrm{ppb}$, while it is $1400 \mathrm{ppb}$ before doping, which is comparable to the sensitivity of boron-doped graphene under continuous UV light. Electrical characterization and Raman spectral measurements of graphene field-effect transistors confirmed that the increased sensitivity was due to the increased concentration of holes in the graphene after $\mathrm{NO}_{2}$ molecules were adsorbed. However, by stability analysis, it was found that the graphene sensor doped with $\mathrm{NO}_{2}$ was not completely stable, which may have been because there were no covalent bonds between the $\mathrm{NO}_{2}$ and graphene.

Similarly to graphene doped with molecules, Impeng et al. analyzed the feasibility of embedding $\mathrm{MnN}_{4}$ molecules (see Fig.2 for the optimized structure) into graphene to increase its performance as a sensor of 13 gas molecules $\left(\mathrm{CO}, \mathrm{CO}_{2}, \mathrm{NO}, \mathrm{NO}_{2}, \mathrm{~N}_{2} \mathrm{O}, \mathrm{SO}_{2}, \mathrm{NH}_{3}, \mathrm{H}_{2} \mathrm{O}, \mathrm{H}_{2} \mathrm{~S}\right.$, $\mathrm{CH}_{4}, \mathrm{O}_{2}, \mathrm{H}_{2}$, and $\mathrm{N}_{2}$ ). ${ }^{(58)}$ Their first-principles calculation results showed that $\mathrm{CO}, \mathrm{NO}$, and $\mathrm{NO}_{2}$ are strongly adsorbed on the $\mathrm{MnN}_{4}$-doped graphene, which represented chemical adsorption. The adsorption energies, amounts of charge transfer, and total magnetic moments for the 13 gases are shown in Table 1. Additionally, the calculated recovery times for the sensing of NO, $\mathrm{CO}$, and $\mathrm{NO}_{2}$ were calculated to be $2.5 \times 10^{14}, 1.7$, and $8275 \mathrm{~s}$ at $423 \mathrm{~K}$, respectively. Taking into account the interactions, charge transfer, magnetic moment, and recovery time between the gases and $\mathrm{MnN}_{4}$-GP, it was found that $\mathrm{MnN}_{4}$-doped graphene is an ideal candidate for $\mathrm{CO}$ detection with a short recovery time.

\subsubsection{Nonmetallic doping}

Owing to their valence electronic configurations and atomic size, dopants cause two major transformations: the destruction of the pristine graphene's hexagonal symmetry and the alteration of the electronic structure. These changes in turn influence the properties of the doped graphene such as the bandgap, magnetic moment, thermal stability, electron mobility, spin densities, reactivity, optical characteristics, and photoresponses. ${ }^{(59)}$ In the study of graphene doping, $\mathrm{B}, \mathrm{C}$, and $\mathrm{N}$ belong to adjacent elements within the same row, and their atomic radii are similar. Furthermore, the N-doped sheets behave as a donor (n-type semiconductor) and B-doped

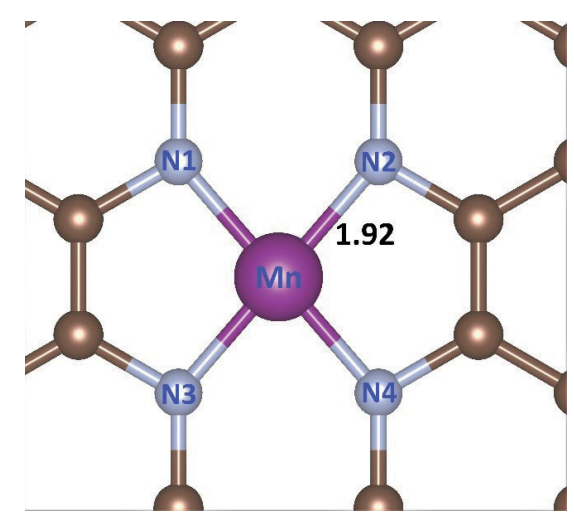

(a)

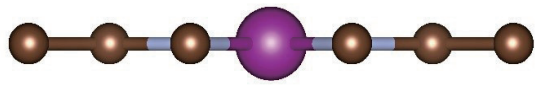

(b)

Fig. 2. (Color online) Optimized structure of $\mathrm{MnN}_{4}$-doped graphene: (a) top and (b) side views. ${ }^{(58)}$ 
Table 1

Adsorption energies, amounts of charge transfer, and total magnetic moments for 13 gases. $E_{a d s}(\mathrm{eV})$ : adsorption energy, $\Delta q$ : amounts of charge transfer from $\mathrm{MnN}_{4}$-doped graphene to gas molecule, $M$ : total magnetic moments (charge in $M(\Delta M)$ ) upon gas adsorption for 13 gas molecules. ${ }^{(58)}$

\begin{tabular}{lcrl}
\hline $\mathrm{Gas}$ & $E_{a d s}(\mathrm{eV})$ & $\Delta q(\mathrm{e})^{1}$ & $M(\Delta M)(\mu \mathrm{B})^{2}$ \\
\hline $\mathrm{NO}$ & -2.30 & -0.43 & $0.13(2.88)$ \\
$\mathrm{NO}_{2}$ & -1.42 & -0.55 & $2.01(1.00)$ \\
$\mathrm{O}_{2}$ & -1.32 & -0.72 & $2.74(0.27)$ \\
$\mathrm{CO}$ & -1.11 & -0.29 & $1.04(1.97)$ \\
$\mathrm{SO}_{2}$ & -0.51 & -0.44 & $2.85(0.16)$ \\
$\mathrm{NH}_{3}$ & -0.42 & 0.09 & $3.01(0.00)$ \\
$\mathrm{H}_{2} \mathrm{O}$ & -0.21 & 0.03 & $3.01(0.00)$ \\
$\mathrm{H}_{2} \mathrm{~S}$ & -0.18 & 0.06 & $3.01(0.00)$ \\
$\mathrm{CO}_{2}$ & -0.03 & -0.01 & $3.01(0.00)$ \\
$\mathrm{N}_{2} \mathrm{O}$ & -0.05 & -0.03 & $3.01(0.00)$ \\
$\mathrm{CH}_{4}$ & -0.03 & 0.00 & $3.01(0.00)$ \\
$\mathrm{N}_{2}$ & -0.03 & -0.09 & $2.98(0.03)$ \\
$\mathrm{H}_{2}$ & -0.02 & 0.00 & $3.01(0.00)$ \\
\hline
\end{tabular}

${ }^{1}$ A negative value of $\Delta q$ indicates the transfer of an electron from the $\mathrm{MnN}_{4}$-doped graphene to the gas molecule.

${ }^{2}$ The magnetic moment of bare $\mathrm{MnN}_{4}$-doped graphene is $-3.01 \mu \mathrm{B}$.

sheets behave as acceptors (p-type semiconductors). ${ }^{(60)}$ The addition of $\mathrm{N}$ atom in the sheets increases the number of delocalized electrons and the addition of $\mathrm{B}$ atoms increases the number of localized electrons in the system. Therefore, B- and N-doped graphene have received extensive attention.

Shaik et al. reported a chemiresistive sensor fabricated using N-doped graphene nanosheets for the detection of $\mathrm{NO}_{2}$ gas at room temperature. ${ }^{(61)}$ The reported sensor exhibited excellent characteristics, including a small detection limit of $120 \mathrm{ppb}$ (at signal/noise $=3$ ). The substitution of nitrogen atoms increases the number of adsorption sites for gas molecules on doped graphene, thus improving the detection sensitivity of adsorbed gas molecules. Compared with graphene nanosheets at room temperature, the sensor coated with $\mathrm{N}$-doped graphene nanosheets has a good response to $\mathrm{NO}_{2}$. Furthermore, under UV irradiation, the recovery of the sensor is considerably accelerated.

Doping multiple layers of graphene is also a means of enhancing gas sensitivity. Srivastava et al. proposed B-doped few-layer graphene (BFLGr) for enhanced $\mathrm{NH}_{3}$ gas sensing, ${ }^{(62)}$ where BFLGr nanosheets were synthesized by a low-pressure chemical vapor deposition (LPCVD) method. They observed that the graphene sensor exhibited an extremely quick response for ammonia gas sensing with fast recovery under ambient conditions.

Recently, researchers have shown that the metal-free dual doping of, for example, B, N, P, O, and $\mathrm{S}$ can synergistically and considerably affect the reactive sites because of the changes in charge redistribution in doped graphene. ${ }^{(60,63-65)}$ Importantly, the catalytic activity of $\mathrm{N}$, $\mathrm{O}$-codoped graphene for achieving high-efficiency hydrazine oxidation has been demonstrated experimentally and double doping with $\mathrm{P}$ and $\mathrm{N}$ can markedly increase chemical adsorption capacity. ${ }^{(66-68)}$ 


\subsubsection{Metallic doping}

The adsorption of $\mathrm{SO}_{2}$ onto various heteroatom-doped (B, N, Al, Si, Cr, Mn, Ag, Au, and Pt) graphenes was analyzed using density functional theory (DFT) by Shao et al. ${ }^{(69)}$ For a quick reference, a comparison of graphenes doped with these elements is presented in Table 2. The results showed that the adsorption capacity of $\mathrm{SO}_{2}$ gas molecules on pristine graphene, B-doped graphene, and $\mathrm{N}$-doped graphene is weak, while graphenes doped with the other atoms exhibited strong chemisorption. Among the doped graphenes, Cr- and Mn-doped graphenes are the best choices for $\mathrm{SO}_{2}$ sensors. Research has shown that the introduction of appropriate dopants can significantly improve the $\mathrm{SO}_{2}$ sensitivity of graphene-based chemical gas sensors.

Aluminum (Al) is a common TM element, and AlG has also been extensively studied by researchers. Sun et al. investigated the adsorption of HF gas molecules on both pristine and AlG sheets by first-principles calculations. ${ }^{(70)}$ They showed that the charge transfer capacity of AlG with adsorbed HF molecules is 24 times than that of the original graphene. Compared with IG, AlG has a higher adsorption energy and a shorter connection distance with HF molecules. On the other hand, under an external electric field of 0.013 a.u., HF molecules adsorbed on AlG can be reactivated. Thus, $\mathrm{AlG}$ is a promising novel sensor for detecting HF gas.

Three-dimensional (3D) TM atoms can significantly improve the adsorption activity of graphene. Zhao and coworkers have proven that the introduction of dopants such as TM ( $\mathrm{Sc}, \mathrm{Ti}$, $\mathrm{V}, \mathrm{Cr}$, and $\mathrm{Mn}$ ) atoms enhances the sensitivity and adsorption properties of pristine graphene towards NO. ${ }^{(71)}$ The calculated results are listed in Table 3. By comparing the changes in the conductivity and magnetic moment of these molecules after adsorption, it can be observed that Mn-doped graphene changes from metallic to semiconducting after adsorbing NO molecules, while it maintains its metallicity with the adsorption of $\mathrm{N}_{2}$ and $\mathrm{O}_{2}$ molecules, indicating that Mn-doped graphene is selective to NO in air. After adsorbing NO molecules, the bandgap of graphene doped with $\mathrm{Ti}, \mathrm{Cr}$, and $\mathrm{Mn}$ changes. Previous reports have shown that the change in the bandgap leads to a larger variation of electrical conductivity, indicating that doping can regulate

Table 2

Comparison of graphenes doped with these elements. $E_{a d s}(\mathrm{eV})$ : adsorption energy, $\Phi(\mathrm{O}-\mathrm{S}-\mathrm{O})\left({ }^{\circ}\right)$ : bond angle, $d(\AA)$ : distance between adjacent atoms, $Q$ (e): Bader charge for the most stable adsorption configurations of $\mathrm{SO}_{2}$ on $\mathrm{IG}$ and XG (X-doped graphene) $)^{1}$. ${ }^{(69)}$

\begin{tabular}{lcccccccccc}
\hline & $\mathrm{IG}$ & $\mathrm{BG}$ & $\mathrm{NG}$ & $\mathrm{AlG}$ & \multicolumn{1}{c}{$\mathrm{SiG}$} & \multicolumn{1}{c}{$\mathrm{PtG}$} & $\mathrm{MnG}$ & $\mathrm{CrG}$ & $\mathrm{AgG}$ & $\mathrm{AuG}$ \\
\hline$E_{\text {ads }}(\mathrm{eV})$ & 0.012 & 0.205 & 0.172 & 1.262 & 0.902 & 1.018 & 1.729 & 1.675 & 0.968 & 1.284 \\
$\Phi\left(^{\circ}\right)$ & 118.74 & 118.29 & 117.18 & 113.36 & 111.00 & 114.86 & 114.20 & 113.41 & 115.23 & 114.63 \\
$d \mathrm{~S}-\mathrm{O}^{2}(\AA)$ & 1.459 & 1.460 & 1.476 & 1.566 & 1.627 & 1.566 & 1.584 & 1.585 & 1.543 & 1.581 \\
$d \mathrm{X}-\mathrm{C}^{3}(\AA)$ & - & 1.486 & 1.409 & 1.899 & 1.774 & 1.944 & 1.805 & 1.853 & 2.093 & 2.145 \\
$d \mathrm{~S}-\mathrm{M}^{4}(\AA)$ & 3.279 & 3.162 & 3.478 & 1.825 & 1.737 & 2.229 & 1.905 & 1.927 & 2.173 & 2.167 \\
$Q^{5}(\mathrm{e})$ & -0.077 & -0.110 & -0.263 & -0.744 & -0.959 & -0.550 & -0.599 & -0.672 & -0.454 & -0.479 \\
\hline
\end{tabular}

\footnotetext{
${ }^{1} \mathrm{X}$ represents the dopant.

${ }^{2}$ The longer $\mathrm{S}-\mathrm{O}$ bond length of the $\mathrm{SO}_{2}$ molecule.

${ }^{3}$ The nearest distance among $\mathrm{X}$ and three adjacent $\mathrm{C}$ atoms.

${ }^{4}$ The nearest distance among the graphene sheet and the three atoms of the $\mathrm{SO}_{2}$ molecule.

${ }^{5} \mathrm{~A}$ negative number means charge transfer from graphene to $\mathrm{SO}_{2}$.
} 
Table 3

Calculation results for NO molecule adsorption on graphenes doped with TM (Sc, Ti, V, Cr, and Mn). ${ }^{(71)} d(\AA)$ : the smallest distance between the doped atom and the adsorbed $\mathrm{NO}\left(\mathrm{N}_{2}, \mathrm{O}_{2}\right)$ molecule. $E_{a d s}(\mathrm{eV})$ : adsorption energy. $E_{\text {ads }}(\mathrm{eV})$ : energy gap. $M(\mu \mathrm{B})$ : the total magnetic moment.

\begin{tabular}{llllll}
\hline $\mathrm{TM}$ & $\mathrm{Gas}$ & $d(\AA)$ & $E_{a d s}(\mathrm{eV})$ & $E_{g}(\mathrm{eV})$ & $M(\mu \mathrm{B})$ \\
\hline \multirow{3}{*}{$\mathrm{Sc}$} & $\mathrm{NO}$ & 2.07 & -1.37 & Metallic & 1.48 \\
& $\mathrm{~N}_{2}$ & 2.33 & -0.45 & Metallic & 0 \\
& $\mathrm{O}_{2}$ & 1.99 & -2.84 & Metallic & 0.51 \\
\hline \multirow{4}{*}{$\mathrm{Ni}$} & $\mathrm{NO}$ & 1.95 & -1.61 & Metallic & 0.92 \\
& $\mathrm{~N}_{2}$ & 2.20 & -0.58 & 0.42 & 0 \\
& $\mathrm{O}_{2}$ & 1.92 & -3.23 & Metallic & 0.42 \\
\hline \multirow{4}{*}{$\mathrm{V}$} & $\mathrm{NO}$ & 1.97 & -2.40 & Metallic & 0.58 \\
& $\mathrm{~N}_{2}$ & 2.07 & -0.86 & 0.50 & 0.93 \\
& $\mathrm{O}_{2}$ & 1.83 & -4.36 & Metallic & 0 \\
\hline \multirow{3}{*}{$\mathrm{Cr}$} & $\mathrm{NO}$ & 1.85 & -3.04 & Metallic & 0.40 \\
& $\mathrm{~N}_{2}$ & 1.97 & -1.01 & 0.31 & 1.71 \\
& $\mathrm{O}_{2}$ & 1.81 & -4.35 & 0.46 & 0.32 \\
\hline \multirow{4}{*}{$\mathrm{Mn}$} & $\mathrm{NO}$ & 1.70 & -2.49 & 0.12 & 0.45 \\
& $\mathrm{~N}_{2}$ & 1.91 & -1.07 & 0.46 & 0.81 \\
& $\mathrm{O}_{2}$ & 1.83 & -3.52 & 0.37 & 1.41 \\
\hline
\end{tabular}

the sensitivity of graphene to gas molecules. ${ }^{(72)}$ In addition, the magnetic moment of graphene doped with $\mathrm{Sc}$ and Ti changes dramatically after the adsorption of NO molecules, but the doped graphenes remain nonmagnetic after the adsorption of $\mathrm{N}_{2}$. Although the adsorption of $\mathrm{O}_{2}$ changes the magnetic moment in Sc- and Ti-doped graphenes, the change is much smaller than that after the adsorption of $\mathrm{NO}$ molecules.

Noble metal NPs selectively adsorb gas molecules and catalyze the dissociation of adsorbed gases, so they are preferred materials for gas sensors. Noble metal nanostructures hybridized with graphene possess high catalytic activity because of their size effect; moreover, graphene can transfer the electrons acquired from the catalytic process of the noble metal to electrodes, which may accelerate the catalytic process.

Lange et al. prepared a composite material by depositing graphene and Pd NPs layer by layer on a gold electrode. ${ }^{(73)}$ The composite material can be used as a sensor for hydrogen concentrations ranging from 0.5 to $1 \%$ in air. Pure graphene has poor sensitivity to hydrogen, but the addition of Pd NPs can increase the sensitivity by more than one order of magnitude. The results showed that the material has electrocatalytic activity and can be used for hydrogen detection. The study also found that the effect of humidity on the sensor response is also extremely important for rapid sensor regeneration. Tang et al. proposed a new chemical method for depositing high-density, small, and uniformly distributed Pd NPs on graphene. ${ }^{(74)}$ This method was used to fabricate hydrogen sensors on 3-inch silicon wafers. The sensor operated properly at room temperature. In particular, the sensor had a short recovery time under light.

The adsorption capacity and stability of Pt- and Pd-doped graphene for hydrogen were further investigated by Wang et al. in 2019. ${ }^{(75)}$ They examined the stability of Pt- or Pd-doped graphene at various concentrations and its sensitivity to $\mathrm{H}_{2}$. The results showed that $\mathrm{Pt}$ or Pd atoms can improve the conductivity of graphene, and the stability of Pt doping is greater than 
that of Pd doping. In addition, by doping different amounts of Pt atoms in graphene, they found that the conductivity of doped graphene could be further improved by increasing the doping concentration. However, a higher doping concentration is not conducive to the overall performance of the system. Thus, $\mathrm{Pt}_{1}$ - and $\mathrm{Pt}_{2}$-doped graphene can achieve a promising compromise between the stability and electrical conductivity of the system, where $\mathrm{Pt}_{1}$-doped graphene has the stronger adsorption effect on $\mathrm{H}_{2}$ (the subscript represents the number of dopant atoms).

Graphene doped with Pd has shown high sensitivity and strong binding with small gas molecules such as $\mathrm{CO}, \mathrm{NH}_{3}, \mathrm{O}_{2}$, and $\mathrm{NO}_{2} \cdot{ }^{(72)}$ It was discovered that IG has weak physical adsorption on the four gas molecules, where the adsorption energy ranges from 0.08 to $0.24 \mathrm{eV}$. Moreover, the electronic properties of IG are only sensitive to the presence of $\mathrm{O}_{2}$ and $\mathrm{NO}_{2}$ molecules. By contrast, Pd-doped graphene has a significantly stronger interaction between the adsorbed molecules and the modified substrate, with the adsorption energy ranging from 1.05 to $2.17 \mathrm{eV}$. Therefore, Pd-doped graphene is suitable for gas sensors.

Inspired by the gas-sensing properties of graphene, Dong et al. grew graphene on germanium through chemical vapor deposition (CVD) and researched $\mathrm{NO}_{2}$ gas sensors based on germanium quantum dot (GeQD)/graphene hybrids. ${ }^{(76)}$ Owing to the introduction of GeQDs on the graphene, the sensitivity of the gas sensors to $\mathrm{NO}_{2}$ was substantially improved. With the optimization of the growth time of GeQDs (600 s), the response sensitivity to $10 \mathrm{ppm} \mathrm{NO}_{2}$ was as high as 3.88 , which is 20 times higher than that of the graphene sensor without GeQD decoration.

\section{Gas Sensors Based on Defective Graphene Materials}

Moving or removing carbon atoms in the graphene plane leads to the breaking of covalently bonded electron pairs. The existence of dangling-bond carbon atoms gives graphene materials new physical and chemical properties, thereby expanding the application potential of graphene materials.

The defects in graphene mainly include two types: point defects and one-dimensional (1D) defects. Vacancies are common graphene point defects, and their presence increases the sensitivity of graphene and enhances the adsorption stability of gas molecules on graphene. Graphene is an ideal medium for studying defects because its 2D nature makes it easy to add, remove, and move carbon atoms as a carbon vacancy defect induces magnetism by breaking the symmetry of nonmagnetic graphene. Moreover, when the graphene produces defects, the energy band will move to create a bandgap at the Fermi level. ${ }^{(77)}$ In addition, the vacancy sites exhibit high reactivity in their interaction with atoms or molecules in the adsorption process.

Zhou et al. investigated the adsorption of a single $\mathrm{SO}_{2}$ molecule on the surface of defect-free graphene and graphene with a single vacancy defect, and found that introducing defects can improve the sensing ability of graphene gas sensors. ${ }^{(78)}$ Table 4 summarizes the calculation results of $\mathrm{SO}_{2}$ adsorption on IG and vacancy-defective graphene (VG). Experiments have shown that, compared with IG, the introduction of holes enhances the adsorption stability and increases the adsorption energy and net charge transfer. The $\mathrm{SO}_{2}$ molecules on different adsorption sites exhibit different adsorption states. In addition, the electronic properties indicated that the 
Table 4

Summary of results for a $\mathrm{SO}_{2}$ molecule adsorbed on IG and VG. $d(\AA)$ : smallest distance between $\mathrm{SO}_{2}$ and the graphene, $E_{a d s}(\mathrm{eV})$ : adsorption energy, $Q(\mathrm{e})$ : charge transfer, $E_{g}(\mathrm{eV})$ : bandgap of the adsorption complex. "Position" represents the direction of approach: for instance, $\mathrm{S}-\mathrm{T}$ means the $\mathrm{S}$ atom of the $\mathrm{SO}_{2}$ molecule approaches the top of the $\mathrm{C}$ atom. ${ }^{(78)}$

\begin{tabular}{lccccc}
\hline System & Position & $d(\AA)$ & $E_{a d s}(\mathrm{eV})$ & $Q(\mathrm{e})$ & $E_{g}(\mathrm{eV})$ \\
\hline \multirow{4}{*}{ IG } & S-T & 3.001 & -0.125 & -0.018 & - \\
& S-H & 3.295 & -0.252 & 0 & - \\
& O-T & 3.101 & -0.134 & -0.023 & - \\
& O-H & 3.368 & -0.314 & -0.067 & - \\
\hline \multirow{4}{*}{ VG } & S-C1 & 1.716 & -1.003 & -0.242 & 0.672 \\
& S-C3 & 1.717 & -1.003 & -0.243 & 0.671 \\
& S-H-VG & 1.711 & -2.383 & -0.315 & 1.706 \\
& O-C1 & 1.352 & -1.900 & -0.325 & 1.188 \\
& O-C3 & 1.355 & -1.901 & -0.290 & 1.037 \\
\hline
\end{tabular}

adsorption of $\mathrm{SO}_{2}$ causes the opening of the bandgap, and the bandgap of all composites increased by $0.5-1.5 \mathrm{eV}$, which can be used as an electronic signal for detecting $\mathrm{SO}_{2}$ gas.

Sungjin et al. developed chemical sensors based on graphene films by using hydrogen plasma or UV/ozone treatment to introduce defects on graphene to induce sensitivity to $\mathrm{NO}_{2}$ gas molecules. ${ }^{(79)}$ The increase in defect concentration was observed to result in a gradual increase in sensitivity, reaching a detection limit lower than ppb level. Moreover, compared with a graphene sensor with defects generated by ozone treatment, the response of the hydrogenated graphene sensor was more reproducible. This was because the defects produced by hydrogenation are stable enough to prevent dehydrogenation due to UV radiation. These results showed that hydrogenated graphene can be used as a $\mathrm{NO}_{2}$ sensor material with high sensitivity and stability at room temperature.

Since defects can efficiently adsorb a target gas, the response of sensors based on graphene has been significantly improved by controlling the defect density. Ma et al. proposed a method of integrating defective graphene and IG to detect $\mathrm{NO}_{2}$ with the purpose of improving the performance of graphene-based gas sensors. ${ }^{(80)}$ They used $\mathrm{Si}^{+}$implantation to control the defect density of defective graphene and adjusted the defect size through $\mathrm{H}_{2}$ etching. The defectivegraphene-based sensor had a response sensitivity of up to $248 \%$ to $100 \mathrm{ppm} \mathrm{NO}_{2}$, which is 13 times that of sensors constructed using pristine graphene.

At present, the large-scale preparation of graphene remains a difficult problem, and even the prepared graphene has some defects. However, many studies have reported that defective graphene has marked advantages in the field of gas detection. Studying the effect of defects on the gas-sensing properties of graphene is also a potential direction for the preparation of outstanding gas sensors.

\section{Binary Graphene-based Hybrids}

Inspired by the enhanced gas-sensing behavior of graphene modified with dopants and defects, some theoretical works have also concentrated on modifying graphene with both dopants and defects. A common research method is to combine metal atom doping with graphene 
defects (such as vacancy defects and Stone-Wales (SW) defects) to study the mechanism by which codoped systems adsorb gas molecules. Metal adsorption and migration at the defect sites show that defect sites tend to act as metal trapping sites, and metal diffusion around the defects is hindered compared with that for the pristine surface. This provides the possibility of enhancing the adsorption capacity of sensitive materials.

DFT and quantum-transport-based calculations have been performed on the adsorption of formaldehyde $\left(\mathrm{H}_{2} \mathrm{CO}\right)$ gas molecules on an undoped SW-defective graphene (SWG) sheet and a sheet doped with $\mathrm{Al}$ atoms. ${ }^{(81)}$ It was found that SWG has better sensing performance than IG in detecting $\mathrm{H}_{2} \mathrm{CO}$ molecules. For the adsorption of $\mathrm{H}_{2} \mathrm{CO}$ molecules, compared with $\mathrm{AlG}$, the binding energy of Al-doped SWG (Al-SWG) is enhanced by the introduction of SW defects. On the other hand, the introduction of SW defects not only increases the stability of the graphene composite, but also makes it easier for $\mathrm{H}_{2} \mathrm{CO}$ molecules to adsorb on its surface, indicating that Al-SWG is more suitable for detecting $\mathrm{H}_{2} \mathrm{CO}$ molecules.

Similarly, Liu et al. theoretically studied the adsorption properties of sulfur dioxide $\left(\mathrm{SO}_{2}\right)$ molecules on graphene composites doped with Al and SW defects by performing DFT calculations. ${ }^{(82)}$ The small changes in the electronic properties indicated the weak adsorption of $\mathrm{SO}_{2}$ molecules on IG and SWG. In contrast, the $\mathrm{SO}_{2}$ molecules interacted strongly with $\mathrm{AlG}$ and Al-SWG. Compared with the AlG system, the introduction of SW defects resulted in a more stable adsorption system. Moreover, the defect dopant greatly changed the conductivity and magnetism of $\mathrm{SO}_{2}$ on Al-SWG, which indicates that Al-SWG sheets are more appropriate for the detection of $\mathrm{SO}_{2}$ molecules. The $\mathrm{AlG}$ with a defect-dopant combination showed high reactivity toward $\mathrm{SO}_{2}$. Table 5 lists the adsorption values of the $\mathrm{SO}_{2}$ and $\mathrm{H}_{2} \mathrm{CO}$ gases on the surface. It was found that by introducing dopants and defects, the sensitivity of graphene-based chemical gas sensors to $\mathrm{SO}_{2}$ was greatly improved, and the introduction of defects into doped graphene is expected to improve the gas-sensing characteristics of sensing materials.

By first-principles study, Ni et al. explored the adsorption properties of mono-vacancy graphene doped with several different elements $(\mathrm{B}, \mathrm{N}, \mathrm{P}, \mathrm{Al})$ to $\mathrm{CH}_{4}$ molecules. ${ }^{(83)}$ They showed that the adsorption performance of Al-doped mono-vacancy graphene (Al-MG) for $\mathrm{CH}_{4}$ molecules is better than those of $\mathrm{B}-\mathrm{MG}, \mathrm{N}-\mathrm{MG}$, and P-MG and that Al-MG has a suitable adsorption strength and apparent bandgap. In addition, the results demonstrated that the binding energy between doped $\mathrm{Al}$ and the mono-vacancy defect is strong, whereas Al-MG exhibited strong adsorption energy and significant charge transfer for $\mathrm{CH}_{4}$ molecules. Al-MG is clearly a promising candidate for $\mathrm{CH}_{4}$ detection applications. Zheng et al. investigated the interaction of

Table 5

Summary of results for $\mathrm{SO}_{2}$ and $\mathrm{H}_{2} \mathrm{CO}$ gas molecules adsorbed on $\mathrm{AlG}$ and Al-SWG. $E_{\text {ads }}(\mathrm{eV})$ : adsorption energy of the molecule-graphene system, $d(\AA)$ : equilibrium molecule graphene distance (defined as the shortest atom-toatom distance), $Q(\mathrm{e})$ : Bader charge transfer, $M(\mu \mathrm{B})$ : magnetic moment of the system.

\begin{tabular}{lccccc}
\hline Gas & Configuration & $E_{a d s}(\mathrm{eV})$ & $d(\AA)$ & $Q(\mathrm{e})$ & $M(\mu \mathrm{B})$ \\
\hline \multirow{2}{*}{$\mathrm{SO}_{2}$} & $\mathrm{AlG}$ & -1.648 & 1.814 & -0.771 & 0.722 \\
& $\mathrm{Al}-\mathrm{SWG}$ & -1.729 & 1.799 & -0.795 & 0.749 \\
\hline \multirow{2}{*}{$\mathrm{H}_{2} \mathrm{CO}$} & $\mathrm{AlG}$ & -1.725 & 1.871 & -0.266 & - \\
& $\mathrm{Al}-\mathrm{SWG}$ & -1.934 & 1.849 & -0.255 & - \\
\hline
\end{tabular}


$\mathrm{CO}_{2}$ gas molecules on pure graphene and Al-, B-, N-, and P-doped mono-vacancy graphenes to explore their potential application as gas sensors. ${ }^{(84)}$ Table 6 summarizes the adsorption parameters of various adsorption configurations for $\mathrm{CO}_{2}$ and $\mathrm{CH}_{4}$ gases. These results and those of Ni et al. mutually verified each other, that is, Al-MG is the most stable, exhibits the largest adsorption energies for $\mathrm{CO}_{2}$, and has the most appreciable impact on the electronic structures.

Studies of oxygen adsorption on graphene modified with TM dopants and defects have shown that VG is a feasible choice for the sensitive detection of oxygen. ${ }^{(85)}$ It was found that the adsorption energy of four different TM ( $\mathrm{Ti}, \mathrm{Cr}, \mathrm{Mn}$, and $\mathrm{Ni}$ ) atoms on VG ranged from -1.92 to $-2.86 \mathrm{eV}$, which exhibited higher stability than IG. The results indicated that $\mathrm{O}_{2}$ molecules are in a dissociated state when adsorbed on VG, and two $\mathrm{O}$ atoms form chemical bonds with $\mathrm{C} 1$ and $\mathrm{C} 2$ atoms. In addition, the introduction of a TM dopant enhances the adsorption strength of $\mathrm{O}_{2}$ molecules on graphene and increases the dissociation barriers of $\mathrm{O}_{2}$ molecules. Furthermore, the configurational magnetic moment is mainly dominated by the 3D orbit of the TM dopant.

DFT calculations and nonequilibrium Green's function formulation results of $\mathrm{H}_{2} \mathrm{~S}$ adsorption showed stronger interactions between $\mathrm{H}_{2} \mathrm{~S}$ and modified graphene than that of IG. ${ }^{\left({ }^{(6)}\right)}$ Graphene modified with defects and TM dopants such as $\mathrm{Ca}, \mathrm{Co}$, and Fe exhibited much higher affinity to $\mathrm{H}_{2} \mathrm{~S}$ than pristine graphene and $\mathrm{B}, \mathrm{N}$-doped graphene. The adsorption energies of these three metal-doped graphenes for $\mathrm{H}_{2} \mathrm{~S}$ molecules were $-0.66,-1.80$, and $-1.92 \mathrm{eV}$, respectively, and the adsorption energies of $\mathrm{Co}$ and $\mathrm{Fe}$ were an order of magnitude higher than that of the pure graphene. The enhanced interactions between $\mathrm{TMs}$ and $\mathrm{H}_{2} \mathrm{~S}$ lead to dramatic changes in the electronic and magnetic properties of graphene. In addition, the adsorption energy of monovacancy defect graphene for $\mathrm{H}_{2} \mathrm{~S}$ molecules can reach $-0.91 \mathrm{eV}$, which is more than five times that of IG and is attributed to the lack of carbon atoms leading to dangling bonds in the defective graphene. In conclusion, it is possible to design $\mathrm{H}_{2} \mathrm{~S}$ chemical sensors with highly improved performances by using graphene nanosheets as sensing materials with appropriate metal dopants or defects.

The potential of metal-decorated graphene for gas adsorption has been investigated and the results were found to be promising (see Fig. 3 for more details). ${ }^{(87)}$ In a DFT-based study of the interactions of several biogas molecules $\left(\mathrm{CH}_{4}, \mathrm{CO}_{2}, \mathrm{H}_{2}, \mathrm{H}_{2} \mathrm{~S}, \mathrm{~N}_{2}\right.$, and $\left.\mathrm{O}_{2}\right)$ with pyridine-like nitrogen-doped graphene (PNG) as well as noble metal (Rh, Pt, Pd)-decorated PNG sheets, compared with biogas adsorption on pristine $\mathrm{PNG}$, higher adsorption ability, higher charge

Table 6

The adsorption parameters of various adsorption configurations for $\mathrm{CO}_{2}$ and $\mathrm{CH}_{4}$ gases. $E_{a d s}(\mathrm{eV})$ : adsorption energy, $d(\AA)$ : the distances of $\mathrm{CH}_{4}$ and $\mathrm{CO}_{2}$ above the graphene surface, $Q(\mathrm{e})$ : charge transfer for $\mathrm{IG}, \mathrm{MG}, \mathrm{B}-\mathrm{MG}$, $\mathrm{N}-\mathrm{MG}, \mathrm{P}-\mathrm{MG}$, and $\mathrm{Al}-\mathrm{MG}$.

\begin{tabular}{lcccccr}
\hline \multirow{2}{*}{ System } & \multicolumn{3}{c}{$\mathrm{CO}_{2}$} & \multicolumn{3}{c}{$\mathrm{CH}_{4}$} \\
\cline { 2 - 7 } & $E_{a d s}(\mathrm{eV})$ & $d(\AA)$ & $Q(\mathrm{e})$ & $E_{a d s}(\mathrm{eV})$ & $d(\AA)$ & $Q(\mathrm{e})$ \\
\hline IG & -0.72 & 3.044 & 2.206 & -0.45 & 3.140 & 0.011 \\
MG & -0.77 & 2.788 & -0.050 & -0.28 & 1.426 & -0.013 \\
B-MG & -0.86 & 2.894 & -0.028 & -0.21 & 0.751 & -0.017 \\
N-MG & -0.81 & 2.997 & -0.012 & -0.63 & 1.555 & -0.006 \\
P-MG & -0.85 & 3.314 & -0.046 & -0.92 & 0.660 & -0.007 \\
Al-MG & -1.54 & 2.126 & -0.317 & -1.96 & 0.687 & 0.032 \\
\hline
\end{tabular}




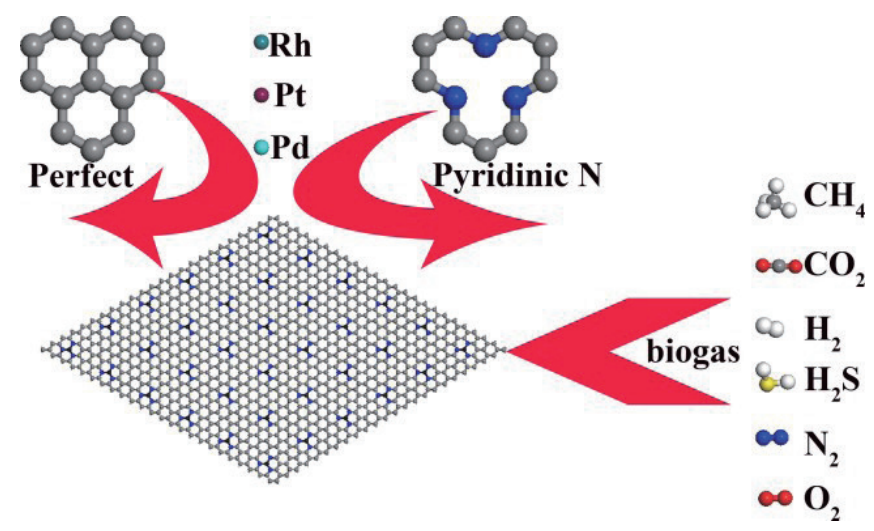

Fig. 3. (Color online) Schematic drawing of biogas adsorption on noble metal (Rh, Pt, Pd) supported on pyridinic N-doped graphene. ${ }^{(87)}$

transfer, and higher orbital hybridization were observed upon the adsorption of these gases on noble metal (Rh, Pt, Pd)-decorated PNG. Table 7 shows the collated correlation analysis values. The results showed that the adsorption energies of the biogases on PNG and noble metal (Rh, Pt, Pd)-decorated PNG decreased in the order $\mathrm{O}_{2}>\mathrm{H}_{2} \mathrm{~S}>\mathrm{N}_{2}>\mathrm{CH}_{4}>\mathrm{CO}_{2}>\mathrm{H}_{2}$, which was consistent with the order of the initiation temperature of catalytic combustion. There is only a weak van der Waals interaction between the biogas $\left(\mathrm{CH}_{4}, \mathrm{CO}_{2}, \mathrm{H}_{2}, \mathrm{H}_{2} \mathrm{~S}, \mathrm{~N}_{2}, \mathrm{O}_{2}\right)$ molecules and the PNG sheet. After decorating the PNG with noble metal atoms, the adsorption intensities significantly improved, indicating that the active sites are transferred from PNG to the supported noble metal atom.

Shukri et al. demonstrated highly sensitive and selective modified sensors prepared from Pddoped VG for the detection of CO and NO. ${ }^{(88)}$ The structure and electronic properties of $\mathrm{CO}$ and NO on graphene (pristine, vacancy-defective, and doped) were investigated. The results indicated the potential of VG and Pd-doped vacancy graphene for molecule sensor applications. Recently, defective graphene comodulated with $\mathrm{N}$ doping and $\mathrm{C}$ vacancies have shown enhanced performance for $\mathrm{NO}_{2}$ gas detection according to first-principles and transport-based calculations. It was clearly demonstrated that the defective graphene with appropriate hetero-doping and vacancy comodulation is promising for enhanced $\mathrm{NO}_{2}$ adsorption and $\mathrm{NO}_{2}$ sensing.

Sulfur hexafluoride $\left(\mathrm{SF}_{6}\right)$ is widely used in gas insulated electrical equipment owing to its excellent insulating and arc-extinguishing properties. However, the partial discharge (PD) of the device can cause $\mathrm{SF}_{6}$ to decompose into other products. Li et al. proposed $\mathrm{N}_{3}$, Ni-doped 555-777 graphene $\left(\mathrm{N}_{3}\right.$, Ni-graphene) as a novel gas sensor to detect the characteristic components of the $\mathrm{SF}_{6}$ decomposition products of $\mathrm{H}_{2} \mathrm{~S}, \mathrm{SO}_{2}, \mathrm{SOF}_{2}$, and $\mathrm{SO}_{2} \mathrm{~F}_{2}$. Note that 555-777 graphene is a double-VG sheet (see Table 8 for more details). ${ }^{(89)}$ The calculation results showed that $\mathrm{N}_{3}$, Ni dopant can improve the conductivity and surface activity of 555-777 graphene. Specifically, the adsorption of $\mathrm{H}_{2} \mathrm{~S}$ and $\mathrm{SO}_{2}$ on the $\mathrm{N}_{3}$, Ni-graphene surface markedly increases the conductivity, while the other two types of gas molecule decrease the conductivity. The sensitivity to $\mathrm{H}_{2} \mathrm{~S}$ is greater than that to $\mathrm{SO}_{2}$ according to the change in the value of the energy gap. It was also found that $\mathrm{N}_{3}$, Ni-graphene can absorb the above four characteristic components stably with high 
Table 7

Collated correlation analysis values. $E_{a d s}(\mathrm{eV})$ : adsorption energy, $Q$ (e): charge transfer, $d(\AA)$ : distance of PNG and noble metal (Rh, Pt, Pd)-decorated PNG during biogas $\left(\mathrm{CH}_{4}, \mathrm{CO}_{2}, \mathrm{H}_{2}, \mathrm{H}_{2} \mathrm{~S}, \mathrm{~N}_{2}, \mathrm{O}_{2}\right)$ adsorption.

\begin{tabular}{|c|c|c|c|c|c|}
\hline Gas & Analyte & PNG & Rh-PNG & Pt-PNG & Pd-PNG \\
\hline \multirow{3}{*}{$\mathrm{CH}_{4}$} & $E_{a d s}(\mathrm{eV})$ & -0.099 & -1.098 & -1.274 & -0.997 \\
\hline & $d(\AA)$ & 2.539 & & $1.813-1.998$ & \\
\hline & $Q(\mathrm{e})$ & 0.009 & 0.128 & 0.306 & 0.124 \\
\hline \multirow{3}{*}{$\mathrm{CO}_{2}$} & $E_{a d s}(\mathrm{eV})$ & -0.080 & -0.263 & -0.285 & -0.213 \\
\hline & $d(\AA)$ & 3.010 & & $2.254-2.394$ & \\
\hline & $Q(\mathrm{e})$ & 0.007 & 0.068 & 0.089 & 0.046 \\
\hline \multirow{3}{*}{$\mathrm{H}_{2}$} & $E_{a d s}(\mathrm{eV})$ & -0.0074 & -0.119 & -0.136 & -0.108 \\
\hline & $d(\AA)$ & 2.670 & & $2.439-2.558$ & \\
\hline & $Q(\mathrm{e})$ & 0.004 & 0.037 & 0.045 & 0.023 \\
\hline \multirow{3}{*}{$\mathrm{H}_{2} \mathrm{~S}$} & $E_{a d s}(\mathrm{eV})$ & -0.232 & -1.742 & -1.868 & -1.698 \\
\hline & $d(\AA)$ & 1.967 & & $2.246-2.290$ & \\
\hline & $Q(\mathrm{e})$ & 0.068 & 0.405 & 0.501 & 0.390 \\
\hline \multirow{3}{*}{$\mathrm{N}_{2}$} & $E_{a d s}(\mathrm{eV})$ & -0.135 & -1.638 & -1.714 & -1.483 \\
\hline & $d(\AA)$ & 3.240 & & $1.914-1.961$ & \\
\hline & $Q(\mathrm{e})$ & 0.011 & 0.287 & 0.374 & 0.269 \\
\hline \multirow{3}{*}{$\mathrm{O}_{2}$} & $E_{a d s}(\mathrm{eV})$ & -0.382 & -1.835 & -1.936 & -1.768 \\
\hline & $d(\AA)$ & 2.214 & & $1.907-2.045$ & \\
\hline & $Q(\mathrm{e})$ & 0.076 & 0.440 & 0.566 & 0.327 \\
\hline
\end{tabular}

Table 8

Structural parameters of the products of $\mathrm{SF}_{6}$ adsorbed on $\mathrm{N}_{3}$, Ni-graphene, and $\mathrm{Pd}_{3}$-graphene surfaces. "Position" represents the direction of approach; for instance, $\mathrm{S}-\mathrm{Ni}$ means that the $\mathrm{H}_{2} \mathrm{~S}$ molecule approaches the Ni atom via the $\mathrm{S}$ atom.

\begin{tabular}{lcccc}
\hline System & Position & $E_{a d s}(\mathrm{eV})$ & \multicolumn{1}{c}{$Q(\mathrm{e})$} & $d(\AA)$ \\
\hline \multirow{3}{*}{$\mathrm{H}_{2} \mathrm{~S}$} & $\mathrm{~S}-\mathrm{Ni}$ & -0.622 & 0.260 & 2.256 \\
& $\mathrm{~S}-\mathrm{Pd}$ & -1.211 & 0.286 & 2.338 \\
& $\mathrm{H}-\mathrm{Pd}$ & -1.185 & 0.279 & 1.868 \\
\hline \multirow{3}{*}{$\mathrm{SO}_{2}$} & $\mathrm{~S}-\mathrm{Ni}$ & -0.769 & -0.037 & 3.536 \\
& $\mathrm{O}-\mathrm{Ni}$ & -1.312 & -0.315 & 1.953 \\
& $\mathrm{~S}-\mathrm{Pd}$ & -1.534 & -0.023 & 2.192 \\
& $\mathrm{O}-\mathrm{Pd}$ & -1.591 & -0.283 & 2.131 \\
\hline \multirow{6}{*}{$\mathrm{SOF}_{2}$} & $\mathrm{~F}-\mathrm{Ni}$ & -0.713 & 0.008 & 2.807 \\
& $\mathrm{O}-\mathrm{Ni}$ & -0.730 & 0.020 & 2.756 \\
& $\mathrm{~S}-\mathrm{Pd}$ & -1.230 & 0.038 & 2.170 \\
& $\mathrm{~F}-\mathrm{Pd}$ & -0.284 & -0.255 & 2.124 \\
& $\mathrm{O}-\mathrm{Pd}$ & -1.282 & -0.132 & 2.299 \\
\hline \multirow{3}{*}{$\mathrm{SO}_{2} \mathrm{~F}_{2}$} & $\mathrm{~F}-\mathrm{Ni}$ & -0.640 & -0.002 & 3.266 \\
& $\mathrm{O}-\mathrm{Ni}$ & -0.727 & 0.019 & 2.741 \\
& $\mathrm{~F}-\mathrm{Pd}$ & -0.920 & -0.705 & 2.014 \\
& $\mathrm{O}-\mathrm{Pd}$ & -0.804 & -0.294 & 2.181 \\
\hline
\end{tabular}

adsorption energies, complex orbital hybridizations, and multilevel charge transfer. The following year, $\mathrm{Li}$ et al. investigated $\mathrm{Pd}_{3}$-cluster-modified 555-777 graphene ( $\mathrm{Pd}_{3}$-graphene) as a novel resistor-type gas sensor to detect $\mathrm{SF}_{6}$ decomposition products. ${ }^{(90)}$ The absence of two carbon atoms does not destroy the original $\mathrm{sp}^{2}$ hybrid orbital network but forms a stable 
topological hole. In their study, $\mathrm{Pd}_{3}$-graphene was used to detect $\mathrm{SF}_{6}$ decomposition products. The results showed that the conductivity of $\mathrm{Pd}_{3}$-graphene was consistently improved by the decrease in $E_{g}$ after gas adsorption. $\mathrm{SOF}_{2}$ gas adsorption led to the largest increase in conductivity among the decomposition products, whereas $\mathrm{SO}_{2} \mathrm{~F}_{2}$ led to the smallest increase. According to the reduced values of $E_{g}$, the sensitivity to the four gases decreased in the order $\mathrm{SOF}_{2}>\mathrm{H}_{2} \mathrm{~S}>\mathrm{SO}_{2}>\mathrm{SO}_{2} \mathrm{~F}_{2}$. It was found that $\mathrm{Pd}_{3}$-graphene can adsorb $\mathrm{SF}_{6}$ decomposition products and that a $\mathrm{Pd}_{3}$-graphene sensor can be employed to evaluate the insulation condition of Geographic Information System (GIS) by detecting these decomposition gases.

\section{Conclusions and Perspectives}

As a single-atom 2D planar crystal, graphene has a wide range of potential applications in the field of sensor materials owing to its unique electronic properties and excellent electron transport capabilities. Chemical sensors are one of the most promising research and application fields of graphene. Graphene-based chemical sensors can sensitively detect the adsorption and desorption of individual gas molecules on the sensor surface with extremely high detection sensitivity. This paper reviewed the recent works of researchers on gas sensing using graphene with internal defects and doped graphene. The purpose was to clarify the current research status of graphene surface functionalization, so as to expand the application potential of graphene materials in the field of detection.

With the development of graphene-based chemical doping research, modified graphenebased sensing materials are expected to play a crucial role in the field of gas sensors. Judging from the perspective of current development trends, the research on graphene surface functionalization can be considered from the following aspects: (1) through surface modification by exploring better doping methods in order to develop more dopants and broaden the application range of doped graphene; (2) by designing more rational adsorption configurations, improving existing research results, and carrying out further processing to enhance the response sensitivity of graphene-based sensors to specific gases; and (3) by combining graphene defects with atomic doping or polymer doping. As a result of advances in research, improved graphene-based sensitive materials are expected to be used extensively in the field of gas detection.

\section{Acknowledgments}

This research was funded by the Science and Technology Research Program of Chongqing Municipal Education Commission (KJQN201901108), the Scientific Research Foundation of Chongqing University of Technology (2019ZD06), the Postgraduate Innovation Program of Chongqing University of Technology (clgycx20202120), and the Scientific Research Foundation of Chongqing University of Technology (2020ZDZ026).

\section{Conflicts of Interest}

The authors declare no conflict of interest. 


\section{References}

1 K. S. Novoselov, A. K. Geim, S. V. Morozov, D. Jiang, Y. Zhang, S. V. Dubonos, I. V. Grigorieva, and A. A. Firsov: Sci. 306 (2004) 666. https://doi.org/10.1126/science.1102896

2 S. Y. Zhou, D. A. Siegel, A. V. Fedorov, and A. Lanzara: Phys. Rev. Lett. 101 (2008) 086402. https://doi. org/10.1103/PhysRevLett.101.086402

3 G. Jimenez-Cadena, J. Riu, and F. X. Rius: Anal. 132 (2007) 1083. 1083. https://doi.org/10.1039/b704562j

4 F. Schedin, A. K. Geim, S. V. Morozov, E. W. Hill, P. Blake, M. I. Katsnelson, and K. S. Novoselov: Nat. Mater. 6 (2007) 652. https://doi.org/10.1038/nmat1967

5 Y. Dan, Y. Lu, N. J. Kybert, Z. Luo, and A. T. C. Johnson: Nano Lett. 9 (2009) 1472. https://doi.org/10.1021/ n18033637

6 J. D. Fowler, M. J. Allen, V. C. Tung, Y. Yang, R. B. Kaner, and B. H. Weiller: ACS Nano 3 (2010) 301. https:// doi.org/10.1021/nn800593m

7 R. K. Joshi, H. Gomez, F. Alvi, and A. Kumar: J. Phys. Chem. C 114 (2010) 6610. https://doi.org/10.1021/ jp100343d

8 F.-L. Meng, Z. Guo, and X.-J. Huang: TrAC, Trends Anal. Chem. 68 (2015) 37. https://doi.org/10.1016/j. trac.2015.02.008

9 Y. H. Zhang, Y. B. Chen, K. G. Zhou, C. H. Liu, J. Zeng, H. L. Zhang, and Y. Peng: Nanotechnology 20 (2009) 185504. https://doi.org/10.1088/0957-4484/20/18/185504

10 Q. Zhou, Y. Yong, X. Su, W. Ju, Z. Fu, C. Wang, and X. Li: J. Iran. Chem. Soc. 15 (2018) 1755. https://doi. org/10.1007/s13738-018-1373-4

11 S. Arunragsa, Y. Seekaew, W. Pon-On, and C. Wongchoosuk: Diamond Relat. Mater. 105 (2020) 107790. https://doi.org/10.1016/j.diamond.2020.107790

12 E. Salih and A. I. Ayesh: Physica E 125 (2021) 114418. https://doi.org/10.1016/j.physe.2020.114418

13 E. Olsson, G. Chai, M. Dove, and Q. Cai: Nanoscale 11 (2019) 5274. https://doi.org/10.1039/C8NR10383F

14 R. Muhammad, Y. Shuai, and H.-P. Tan: Physica E 88 (2017) 115. https://doi.org/10.1016/j.physe.2016.12.012

15 R. Ghanbari, R. Safaiee, M. H. Sheikhi, M. M. Golshan, and Z. K. Horastani: ACS Appl. Mater. Interfaces 11 (2019) 21795. https://doi.org/10.1021/acsami.9b00625

16 W. Wei, J. Nong, G. Zhang, L. Tang, X. Jiang, N. Chen, S. Luo, G. Lan, and Y. Zhu: Sensors (Basel) 17 (2016) 2. https://doi.org/10.3390/s17010002

17 A. V. Singhal, H. Charaya, and I. Lahiri: Crit. Rev. Solid State Mater. Sci. 42 (2017) 499. https://doi.org/10.1080 /10408436.2016.1244656

18 C.-H. Han, D.-W. Hong, I.-J. Kim, J. Gwak, S.-D. Han, and K. C. Singh: Sens. Actuators, B 128 (2007) 320. https://doi.org/10.1016/j.snb.2007.06.025

19 M. Rafique, Y. Shuai, H.-P. Tan, and H. Muhammad: Appl. Surf. Sci. 408 (2017) 21. https://doi.org/10.1016/j. apsusc.2017.02.239

20 R. Muhammad, Y. Shuai, A. Irfan, and T. He-Ping: RSC Adv. 8 (2018) 23688. https://doi.org/10.1039/ C8RA03484B

21 D. Cortes-Arriagada, N. Villegas-Escobar, S. Miranda-Rojas, and A. Toro-Labbe: Phys. Chem. Chem. Phys. 19 (2017) 4179. https://doi.org/10.1039/C5CP05142H

22 Z. Khodadadi: Physica E 99 (2018) 261. https://doi.org/10.1016/j.physe.2018.02.022

23 R. Bhargav and B. Indrani: Functionalized Graphene Nanocomposites and their Derivatives (Elsevier, 2019) p. 261. https://doi.org/10.1016/B978-0-12-814548-7.00015-5

24 Z. Auzar, Z. Johari, S. H. Sakina, N. E. Alias, and M. S. Z. Abidin: Mater. Res. Express 4 (2017). https://doi. org/10.1088/2053-1591/aa598a

25 S. Basu and P. Bhattacharyya: Sens. Actuators, B 173 (2012) 1. https://doi.org/10.1016/j.snb.2012.07.092

26 J.-N. Zhang, L. Ma, M. Zhang, and J.-M. Zhang: Physica E 118 (2020). https://doi.org/10.1016/j. physe.2019.113879

27 X. Jia, H. Zhang, Z. Zhang, and L. An: Superlattices Microstruct. 134 (2019). https://doi.org/10.1016/j. spmi.2019.106235

28 G. Capote Mastrapa and F. L. Freire: J. Sens. 2019 (2019) 1. https://doi.org/10.1155/2019/5492583

29 W. Zhao and Q. Y. Meng: Adv. Mater. Res. 602-604 (2012) 870. https://doi.org/10.4028/www.scientific.net/ AMR.602-604.870

30 P. Seifaddini, R. Ghasempour, M. Ramezannezhad, and A. Nikfarjam: Mater. Res. Express 6 (2019). https://doi. org/10.1088/2053-1591/aafbc4

31 S. Srivastava, P. K. Kashyap, V. Singh, T. D. Senguttuvan, and B. K. Gupta: New J. Chem. 42 (2018) 9550. https://doi.org/10.1039/c8nj00885j 
32 W.-K. Jang, J. Yun, H.-I. Kim, and Y.-S. Lee: Colloid. Polym. Sci. 291 (2012) 1095. https://doi.org/10.1007/ s00396-012-2832-6

33 M. A. Gross, M. J. A. Sales, M. A. G. Soler, M. A. Pereira-da-Silva, M. F. P. da Silva, and L. G. Paterno: RSC Adv. 4 (2014). https://doi.org/10.1039/c4ra01469c

34 T. T. Tung, M. Castro, J.-F. Feller, T. Y. Kim, and K. S. Suh: Org. Electron. 14 (2013) 2789. https://doi. org/10.1016/j.orgel.2013.07.038

35 S. M. Mortazavi Zanjani, M. M. Sadeghi, M. Holt, S. F. Chowdhury, L. Tao, and D. Akinwande: Appl. Phys. Lett. 108 (2016). https://doi.org/10.1063/1.4940128

36 X.-Y. Liang, N. Ding, S.-P. Ng, and C.-M. L. Wu: Appl. Surf. Sci. 411 (2017) 11. https://doi.org/10.1016/j. apsusc.2017.03.178

37 J. Yi, J. M. Lee, and W. I. Park: Sens. Actuators, B 155 (2011) 264. https://doi.org/10.1016/j.snb.2010.12.033

38 S. Jamalzadeh Kheirabadi, R. Ghayour, and M. Sanaee: Physica Scripta 94 (2019) 115801. https://doi. org/10.1088/1402-4896/ab2b75

39 K. Li, N. Li, N. Yan, T. Wang, Y. Zhang, Q. Song, and H. Li: Appl. Surf. Sci. 515 (2020) 146028. https://doi. org/10.1016/j.apsusc.2020.146028

40 S. Shanmugam, S. Nachimuthu, and V. Subramaniam: Mater. Today Commun. 22 (2020) 100714. https://doi. org/10.1016/j.mtcomm.2019.100714

41 X. Zhu, K. Liu, Z. Lu, Y. Xu, S. Qi, and G. Zhang: Physica E 117 (2020) 113827. https://doi.org/10.1016/j. physe.2019.113827

42 X. Dai, T. Shen, J. Chen, and H. Liu: Coatings 10 (2020) 131. https://doi.org/10.3390/coatings10020131

43 N. Baildya, N. N. Ghosh, and A. P. Chattopadhyay: Phys. Lett. A 384 (2020) 126194. https://doi.org/10.1016/j. physleta.2019.126194

44 S. Z. N. Demon, A. I. Kamisan, N. Abdullah, S. A. M. Noor, O. K. Khim, N. A. M. Kasim, M. Z. A. Yahya, N. A. A. Manaf, A. F. M. Azmi, and N. A. Halim: Sens. Mater. 32 (2020) 759. https://doi.org/10.18494/ SAM.2020.2492

45 D. Sun, Y. Luo, M. Debliquy, and C. Zhang: Beilstein J. Nanotechnol. 9 (2018) 2832. https://doi.org/10.3762/ bjnano.9.264

46 Y. Wu, B. Yao, C. Yu, and Y. Rao: Sensors (Basel) 18 (2018). https://doi.org/10.3390/s18040941

47 W. Tian, X. Liu, and W. Yu: Appl. Sci. 8 (2018). https://doi.org/10.3390/app8071118

48 P. S. Wrobel, M. D. Wlodarski, A. Jedrzejewska, K. M. Placek, R. Szukiewicz, S. Kotowicz, K. Tokarska, H. T. Quang, R. G. Mendes, Z. Liu, B. Trzebicka, M. H. Rummeli, and A. Bachmatiuk: Mater. Res. Express 6 (2018). https://doi.org/10.1088/2053-1591/aae6be

49 X. Jia, H. Zhang, Z. Zhang, and L. An: Mater. Chem. Phys. 249 (2020). https://doi.org/10.1016/j. matchemphys.2020.123114

50 E. V. Castro, K. S. Novoselov, S. V. Morozov, N. M. Peres, J. M. dos Santos, J. Nilsson, F. Guinea, A. K. Geim, and A. H. Neto: Phys. Rev. Lett. 99 (2007) 216802. https://doi.org/10.1103/PhysRevLett.99.216802

51 W. Liu, Y. H. Zhao, J. Nguyen, Y. Li, Q. Jiang, and E. J. Lavernia: Carbon 47 (2009) 3452. https://doi. org/10.1016/j.carbon.2009.08.012

52 Y. A. Lv, G. L. Zhuang, J. G. Wang, Y. B. Jia, and Q. Xie: Phys. Chem. Chem. Phys. 13 (2011) https://doi. org/10.1039/clcp20694j

53 M. Rezaei-Sameti and M. Rakhshi: Mol. Phys. 119 (2020) e1822556. https://doi.org/10.1080/00268976.2020.182 2556

54 T. Tanaka, T. Yokoyama, and K. Uchida: IEEE Electron Device Lett. 39 (2018) 1924. https://doi.org/10.1109/ LED.2018.2875892

55 M. Omidi and E. Faizabadi: IEEE Sens. J. 18 (2018) 8642. https://doi.org/10.1109/jsen.2018.2867726

56 Q. H. Wang, Z. Jin, K. K. Kim, A. J. Hilmer, G. L. Paulus, C. J. Shih, M. H. Ham, J. D. Sanchez-Yamagishi, K. Watanabe, T. Taniguchi, J. Kong, P. Jarillo-Herrero, and M. S. Strano: Nat. Chem. 4 (2012) 724. https://doi. org/10.1038/nchem.1421

57 H. He, K. H. Kim, A. Danilov, D. Montemurro, L. Yu, Y. W. Park, F. Lombardi, T. Bauch, K. Moth-Poulsen, T. Iakimov, R. Yakimova, P. Malmberg, C. Muller, S. Kubatkin, and S. Lara-Avila: Nat. Commun. 9 (2018) 3956. https://doi.org/10.1038/s41467-018-06352-5

58 S. Impeng, A. Junkaew, P. Maitarad, N. Kungwan, D. Zhang, L. Shi, and S. Namuangruk: Appl. Surface Sci. 473 (2019) 820. https://doi.org/10.1016/j.apsusc.2018.12.209

59 S. Ullah, Q. Shi, J. Zhou, X. Yang, H. Q. Ta, M. Hasan, N. M. Ahmad, L. Fu, A. Bachmatiuk, and M. H. Rümmeli: Adv. Mater. Interfaces 7 (2020) 2000999. https://doi.org/10.1002/admi.202000999

60 R. Akilan, S. Vinnarasi, S. Mohanapriya, and R. Shankar: Struct. Chem. 31 (2020) 2413. https://doi. org/10.1007/s11224-020-01578-w 
61 M. Shaik, V. K. Rao, M. Gupta, K. S. R. C. Murthy, and R. Jain: RSC Adv. 6 (2016) 1527. https://doi. org/10.1039/C5RA21184K

62 S. Srivastava, S. K. Jain, G. Gupta, T. D. Senguttuvan, and B. K. Gupta: RSC Adv. 10 (2020) 1007. https://doi. org/10.1039/C9RA08707A

63 Z. Zhao and Z. Xia: ACS Catal. 6 (2016) 1553. https://doi.org/10.1021/acscatal.5b02731

64 P. A. Denis: Comput. Theor. Chem. 1097 (2016) 40. https://doi.org/10.1016/j.comptc.2016.10.002

65 P. A. Denis and C. Pereyra Huelmo: Carbon 87 (2015) 106. https://doi.org/10.1016/j.carbon.2015.01.049

66 C. Han and Z. Chen: Appl. Surf. Sci. 471 (2019) 445. https://doi.org/10.1016/j.apsusc.2018.12.019

67 Y. Meng, X. Zou, X. Huang, A. Goswami, Z. Liu, and T. Asefa: Adv. Mater. 26 (2014) 6510. https://doi. org/10.1002/adma.201401969

68 J. Cai, C. Wu, Y. Zhu, K. Zhang, and P. K. Shen: J. Power Sources 341 (2017) 165. https://doi.org/10.1016/j. jpowsour.2016.12.008

69 L. Shao, G. Chen, H. Ye, Y. Wu, Z. Qiao, Y. Zhu, and H. Niu: Eur. Phys. J. B 86 (2013). https://doi.org/10.1140/ epjb/e2012-30853-y

70 Y. Sun, L. Chen, F. Zhang, D. Li, H. Pan, and J. Ye: Solid State Commun. 150 (2010) 1906. https://doi. org/10.1016/j.ssc.2010.07.037

71 D. Zhao, X. Fan, Z. Luo, Y. An, and Y. Hu: Phys. Lett. A 382 (2018) 2965. https://doi.org/10.1016/j. physleta.2018.06.046

72 L. Ma, J.-M. Zhang, K.-W. Xu, and V. Ji: Appl. Surf. Sci. 343 (2015) 121. https://doi.org/10.1016/j. apsusc.2015.03.068

73 U. Lange, T. Hirsch, V. M. Mirsky, and O. S. Wolfbeis: Electrochim. Acta 56 (2011) 3707. https://doi. org/10.1016/j.electacta.2010.10.078

74 X. Tang, P. A. Haddad, N. Mager, X. Geng, N. Reckinger, S. Hermans, M. Debliquy, and J. P. Raskin: Sci. Rep. 9 (2019) 3653. https://doi.org/10.1038/s41598-019-40257-7

75 L. Wang, W. Li, Y. Cai, P. Pan, J. Li, G. Bai, and J. Xu: Mater. Res. Express 6 (2019) 095603. https://doi. org/10.1088/2053-1591/ab2dc0

76 L. Dong, P. Zheng, Y. Yang, M. Zhang, Z. Xue, Z. Wang, G. Liu, P. Li, K. S. Teh, Y. Su, B. Cai, G. Wang, and Z. Di: Nanotechnol. 30 (2019) 074004. https://doi.org/10.1088/1361-6528/aaf3d7

77 F. Banhart, J. Kotakoski, and A. V. Krasheninnikov: ACS Nano 5 (2011) 26. https://doi.org/10.1021/nn102598m

78 Q. Zhou, W. Ju, X. Su, Y. Yong, and X. Li: J. Phys. Chem. Solids 109 (2017) 40. https://doi.org/10.1016/j. jpcs.2017.05.007

79 S. Park, M. Park, S. Kim, S.-G. Yi, M. Kim, J. Son, J. Cha, J. Hong, and K.-H. Yoo: Appl. Phys. Lett. 111 (2017). https://doi.org/10.1063/1.4999263

80 J. Ma, M. Zhang, L. Dong, Y. Sun, Y. Su, Z. Xue, and Z. Di: AIP Adv. 9 (2019). https://doi.org/10.1063/1.5099511

81 X. Qin, Q. Meng, and W. Zhao: Surf. Sci. 605 (2011) 930. https://doi.org/10.1016/j.susc.2011.02.006

82 X.-Y. Liu, J.-M. Zhang, K.-W. Xu, and V. Ji: Appl. Surf. Sci. 313 (2014) 405. https://doi.org/10.1016/j. apsusc.2014.05.223

83 J. Ni, B. Yang, F. Jia, Y. She, S. Song, and M. Quintana: Chem. Phys. Lett. 710 (2018) 221. https://doi. org/10.1016/j.cplett.2018.08.076

84 Z. Zheng and H. Wang: Chem. Phys. Lett. 721 (2019) 33. https://doi.org/10.1016/j.cplett.2019.02.024

85 Q. Zhou, Y. Yong, X. Su, W. Ju, Z. Fu, and X. Li: Int. J. Mod. Phys. B 32 (2018) 33. https://doi.org/10.1016/j. cplett.2019.02.024

86 Y.-H. Zhang, L.-F. Han, Y.-H. Xiao, D.-Z. Jia, Z.-H. Guo, and F. Li: Comput. Mater. Sci. 69 (2013) 222. https:// doi.org/10.1016/j.commatsci.2012.11.048

87 C. Zhao and H. Wu: Appl. Surf. Sci. 435 (2018) 1199. https://doi.org/10.1016/j.apsusc.2017.11.146

88 M. S. M. Shukri, M. N. S. Saimin, M. K. Yaakob, M. Z. A. Yahya, and M. F. M. Taib: Appl. Surf. Sci. 494 (2019) 817. https://doi.org/10.1016/j.apsusc.2019.07.238

89 J. Li, L. Pang, K. He, and L. Zhang: IEEE Access 7 (2019) 145567. https://doi.org/10.1109/ACCESS.2019.2945469

90 J. Li, L. Pang, F. Cai, X. Yuan, and F. Kong: Sensors (Basel) 20 (2020) 4188. https://doi.org/10.3390/s20154188 


\section{About the Authors}

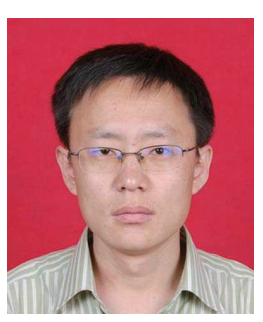

Qingwei Zhang received his Ph.D. degree from the University of Electronic Science and Technology of China. Since 2018, he has been a lecturer at Chongqing University of Technology. His research interests are in 2D material sensors. (zhangqingwei@cqut.edu.cn)

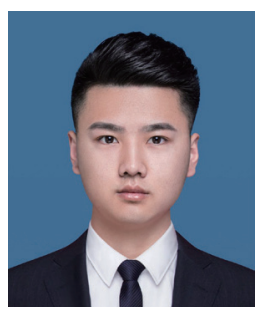

Yanjie Xu received his B.S. degree from Shandong Technology and Business University, China, in 2019. Since 2019, he has been studying for a master's degree at Chongqing University of Technology. His research interests are in 2D material sensors. (xuyanjie@2019.cqut.edu.cn)

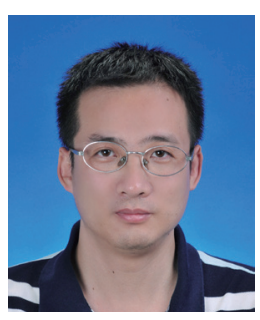

Jun'an Zhang received his Ph.D. degree from the University of Electronic Science and Technology of China. Since 2017, he has been an associate professor at Chongqing University of Technology. His research interests are in sensor processing chip design. (zja2017@cqut.edu.cn)

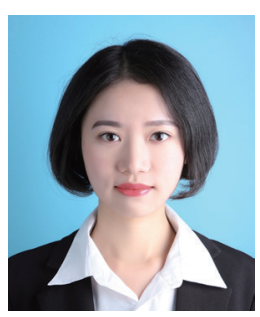

Yunhua Lu received her Ph.D. degree from East China University of Science and Technology. Since 2020, she has been a lecturer at Chongqing University of Technology. Her research interests are in the application of machine learning. (yunhualul@163.com)

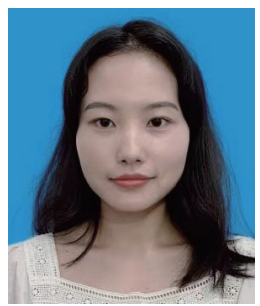

Jiangling Tian received her B.S. degree from Yangtze Normal University, China, in 2020. Since 2020, she has been studying for a master's degree at Chongqing University of Technology. Her research interests are in 2D material sensors. (tianjiangling@2020.cqut.edu.cn) 
